\title{
Structural study of liquid rare earth metals from charged hard sphere reference fluid
}

\author{
P.B.Thakor, P.N.Gajjar, A.R.Jani \\ Department of Physics, Sardar Patel University, \\ Vallabh Vidyanagar 388 120, Gujarat, India
}

Received August 27, 2001

The present article deals with the investigation of structure factor, $s(q)$; radial distribution function, $g(r)$ and interatomic distance, $r_{1}$ of liquid rare earth metals, Nd, Dy, Ho, Er and Lu by adopting Charged Hard Sphere (CHS) reference fluid. To describe electron-ion interaction, our well established model potential along with the dielectric function due to Taylor is used. Good agreement between present and experimental findings is concluded.

Key words: pseudopotential, structure factor, radial distribution function, rare earth metals

PACS: $71.15 . H, 61.25 . M$

\section{Introduction}

The structure factor $S(q)$, is one of the important properties to study the various electronic, magnetic, static and dynamic properties of a material, in liquid states, which is a measure of particle correlations in the reciprocal space. The charged hard sphere (CHS) model is very useful to evaluate the structure factor of metals in liquid state [1-6]. Such a system of CHS in a uniform background of electrons has been solved exactly in a mean spherical approximation by Palmer and Weeks [5]. According to CHS model, the reference system consists of Coulombically interacting positively charged point charges in a uniform background of conduction electrons. Though the CHS method has proved to be very useful for explaining structural properties of liquid metals, the study of liquid rare earth metals using CHS is limited [3]. Gopala Rao and Bandyopadhyay [3] have reported the structure factor, $S(q)$; radial distribution function, $g(r)$; and interatomic distance, $r_{1}$ of the nearest neighbour atoms for Nd, Dy, Ho, Er and Lu by employing CHS reference fluid with Ashcroft empty core model potential. They have fitted the input parameters like effective valency $(\mathrm{Z})$, potential parameter $\left(r_{\mathrm{c}}\right)$ and hard sphere diameter $(\sigma)$ in such a way that a good agreement with experimental findings should be obtained. 
The present paper deals with the structural studies of some liquid rare earth metals, which reports the structure factor, $S(q)$; radial distribution function, $g(r)$ and interatomic distance, $r_{1}$ of the nearest neighbour atoms for Nd, Dy, Ho, Er and $\mathrm{Lu}$. The important aspect of the present investigation is to make the computation free from any fitting procedure to reproduce correct experimental data as it was done by Gopala Rao and Bandyopadhyay [3].

Here, our well established single parametric local pseudopotential is used to represent the electron-ion interaction. The present model potential in real space is of the form $[6-12]$

$$
V(r)= \begin{cases}0, & r<r_{\mathrm{c}} \\ -\left(Z e^{2} / r\right)\left[1-\exp \left(-r / r_{\mathrm{c}}\right)\right], & r \geqslant r_{\mathrm{c}}\end{cases}
$$

The corresponding bare-ion form factor in the reciprocal space is given as [6-12]

$$
V_{\mathrm{B}}(q)=\left(\frac{-4 \pi Z e^{2}}{\Omega q^{2}}\right)\left[\cos \left(q r_{\mathrm{c}}\right)-\left\{\frac{\left(q r_{\mathrm{c}}\right) \exp (-1)}{1+q^{2} r_{\mathrm{c}}^{2}}\right\}\left\{\sin \left(q r_{\mathrm{c}}\right)+\left(q r_{\mathrm{c}}\right) \cos \left(q r_{\mathrm{c}}\right)\right\}\right] \text {. }
$$

Here $Z, \Omega, q$ and $r_{\mathrm{c}}$ are the valency, atomic volume, wave vector and the parameter of the potential, respectively. In the present investigations, the parameter of the potential is determined using [13],

$$
r_{\mathrm{c}}=0.51(Z)^{-1 / 3} R_{\mathrm{a}}
$$

where $R_{\mathrm{a}}$ is the atomic radius.

This model potential is the modified version of the Ashcroft's empty core model. It is continuous in $\mathbf{r}$ space. Here we have introduced some repulsive part outside the core which vanishes faster than only Coulomb potential $-Z e^{2} / r$ as $r \rightarrow \infty$. Moreover, it may be noted that the inclusion of this repulsive term outside the core makes the effective core smaller than the ionic radius of a free ion [6-12].

\section{Theory}

The CHS model was studied within the framework of a mean spherical approximation inside the core and outside the core, a perturbation in the form of Coulomb interaction is assumed to act by Palmer and Weeks [5]. In the CHS approximation, the direct correlation function is given by $[3,4,6]$

$$
C_{0}(r)=\left\{\begin{array}{lr}
A+B\left(\frac{r}{\sigma}\right)+C\left(\frac{r}{\sigma}\right)^{2}+D\left(\frac{r}{\sigma}\right)^{3}+E\left(\frac{r}{\sigma}\right)^{5}, & r<\sigma, \\
-\gamma /\left(\frac{r}{\sigma}\right), & r>\sigma .
\end{array}\right.
$$

The coefficients involved in equation (2.1) are given by,

$$
\begin{aligned}
& A=-\frac{(1+2 \eta)^{2}}{(1-\eta)^{4}}+\frac{\mathcal{Q}^{2}}{4(1-\eta)^{2}}-\frac{(1+\eta) \mathcal{Q} K}{12 \eta}-\frac{\left(5+\eta^{2}\right)^{2}}{60 \eta} \\
& B=6 \eta M^{2}, \quad C=\frac{K^{2}}{6}, \quad D=\left(\frac{\eta}{2}\right)\left(A-K^{2} U\right), \quad E=\frac{\eta K^{2}}{60}
\end{aligned}
$$


with

$$
\begin{aligned}
& \mathcal{Q}=\frac{(1+2 \eta)}{(1-\eta)}\left[1-\left\{\frac{1+2(1-\eta)^{3} K}{(1+2 \eta)^{2}}\right\}^{1 / 2}\right], \\
& M=\frac{\mathcal{Q}^{2}}{24 \eta}-\frac{(1+0.5 \eta)}{(1-\eta)^{2}}, \quad U=\frac{\left(1+\eta-\eta^{2} / 5\right)}{12 \eta}-\frac{(1-\eta) Q}{12 \eta K} \\
& \gamma=\beta \frac{(Z e)^{2}}{\varepsilon_{0} \sigma}, \quad K=(24 \eta \gamma)^{1 / 2}, \quad \eta=\left(\frac{\pi}{6}\right) \rho \sigma^{3} .
\end{aligned}
$$

Here, $\gamma, K$ and $\eta$ are the dimensionless variables, which represent the Coulomb interaction potential, the inverse screening length due to Debye and Huckel and packing fraction, respectively. Here, $\sigma$ is the charged hard sphere diameter, $Z e$ is the ionic charge, $\beta=1 / k_{\mathrm{B}} T, k_{\mathrm{B}}$ is Boltzmann constant, $T$ is absolute temperature of the system, $\varepsilon_{0}$ is the dielectric constant of the medium. Since the electron background is uniform, its dielectric constant is unity.

The static structure factor $S_{0}(q)$ of the reference system is related to its direct correlation function in the following form $[3,4,6]$ :

$$
S_{0}(q)=\frac{1}{\left[1-\rho C_{0}(q)\right]}
$$

The mathematical expression for $\rho C_{0}(q)$ is given by $[3,4,6]$

$$
\begin{aligned}
\rho C_{0}(q) & =\left(\frac{24 \eta}{q^{6}}\right)\left[A q^{3}(\sin q-q \cos q)\right. \\
& +B q^{2}\left\{2 q \sin q-\left(q^{2}-2\right) \cos q-2\right\} \\
& +C q\left\{\left(3 q^{2}-6\right) \sin q-\left(q^{2}-6\right)\right\} \\
& +D\left\{\left(4 q^{2}-24\right) q \sin q-\left(q^{4}-12 q^{2}+24\right) \cos q+24\right\} \\
& +E\left\{6\left(q^{4}-20 q^{2}+120\right) q \sin q-\left(q^{6}-30 q^{4}+360 q^{2}-720\right) \cos q-720\right\} / q^{2} \\
& \left.-\gamma q^{4} \cos q\right]
\end{aligned}
$$

Here $q$ is expressed in units of $\sigma^{-1}$.

The effect of responding electrons on the ionic motion is taken into account by assuming a weak coupling between valence electrons and ions which is also the basis of a standard pseudopotential approach. Within a linear screening approximation, the structure factor of a liquid metal is given by $[3,4,6]$

$$
S(q)=\frac{S_{0}(q)}{\left[1+\rho \beta \bar{V}(q) S_{0}(q)\right]}
$$

with

$$
\bar{V}(q)=\frac{V_{\mathrm{B}}^{2}(q)}{\phi(q)}\left[\frac{1}{\varepsilon(q)}-1\right],
$$

which is the attractive screening correlation to the direct ion-ion potential, $\phi(q)=$ $4 \pi e^{2} / q^{2}$ is the Fourier transform of bare Coulombic interaction between two electrons 
and $V_{\mathrm{B}}(q)$ is the bare ion pseudopotential. The modified dielectric function $\varepsilon(\mathrm{q})$ has the following form

$$
\varepsilon(q)=1+[1-f(q)]\left[\varepsilon_{\mathrm{H}}(q)-1\right],
$$

with the static Hartree dielectric function $\varepsilon_{\mathrm{H}}(q)$ represented by

$$
\varepsilon_{\mathrm{H}}(q)=1+\frac{m e^{2}}{2 \pi h^{2} k_{\mathrm{F}} Y^{2}}\left[1+\frac{\left(1-Y^{2}\right)}{2 Y} \ln \left|\frac{1+Y}{1-Y}\right|\right],
$$

where $m$ is the ionic mass, $h$ the Planck's constant, $k_{\mathrm{F}}$ the Fermi wave vector, $e$ is the electronic charge and $Y=q / 2 k_{\mathrm{F}}$.

The local field correction $f(q)$ due to Taylor [14] is used to incorporate the exchange and correlation among the conduction electrons in the dielectric screening

$$
f(q)=\frac{q^{2}}{4 k_{\mathrm{F}}^{2}}\left[1+\frac{0.1534}{\pi k_{\mathrm{F}}}\right] .
$$

The expression for the radial distribution function is given by $[3,6]$

$$
g(r)=1+\left(\frac{1}{2 \pi^{2} \rho r}\right) \int_{0}^{\infty} q\{S(q)-1\} \sin (q r) \mathrm{d} q .
$$

Using this radial distribution function we obtain the interatomic distance, $r_{1}$ of the nearest neighbour atoms. The interatomic distance $r_{1}$ corresponds to the maximum peak of $g(r)$ curve.

\section{Results and discussion}

The constants and parameters used in the present computations of structure factor, $S(q)$ and radial distribution function, $g(r)$ for the liquid rare earth metals are tabulated in table 1.

Figures 1-5 show the computed values of $S(q)$ and $g(r)$ of Nd, Dy, Ho, Er and $\mathrm{Lu}$, respectively along with the experimental findings [15].

Table 1. Parameters and constants used in present calculation.

\begin{tabular}{|c|c|c|c|c|c|c|}
\hline Metal & $T(\mathrm{~K})$ & $\rho\left(\mathrm{gm} / \mathrm{cm}^{3}\right)$ & $\mathrm{Z}$ & $\eta$ & $k_{\mathrm{F}}\left(\AA^{-1}\right)$ & $r_{\mathrm{c}}(\AA)$ \\
\hline Nd & 1473 & 6.78 & 1.5 & 0.40 & 1.0793 & 0.8113 \\
\hline Dy & 1703 & 8.14 & 1.5 & 0.43 & 1.1025 & 0.7899 \\
\hline Ho & 1753 & 8.25 & 1.5 & 0.43 & 1.1020 & 0.7868 \\
\hline Er & 1793 & 8.37 & 1.5 & 0.44 & 1.1022 & 0.7828 \\
\hline Lu & 1953 & 9.18 & 1.5 & 0.44 & 1.1197 & 0.7725 \\
\hline
\end{tabular}



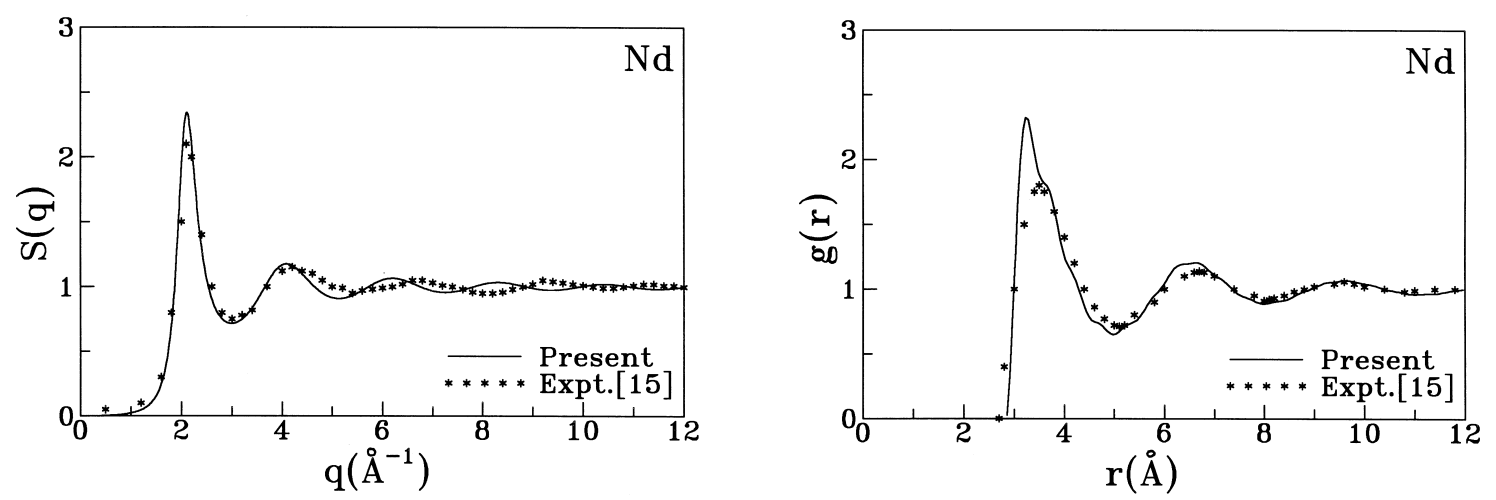

Figure 1. Structure factor, $S(q)$ and radial distribution function, $g(r)$ for $\mathrm{Nd}$ at $1473 \mathrm{~K}$.
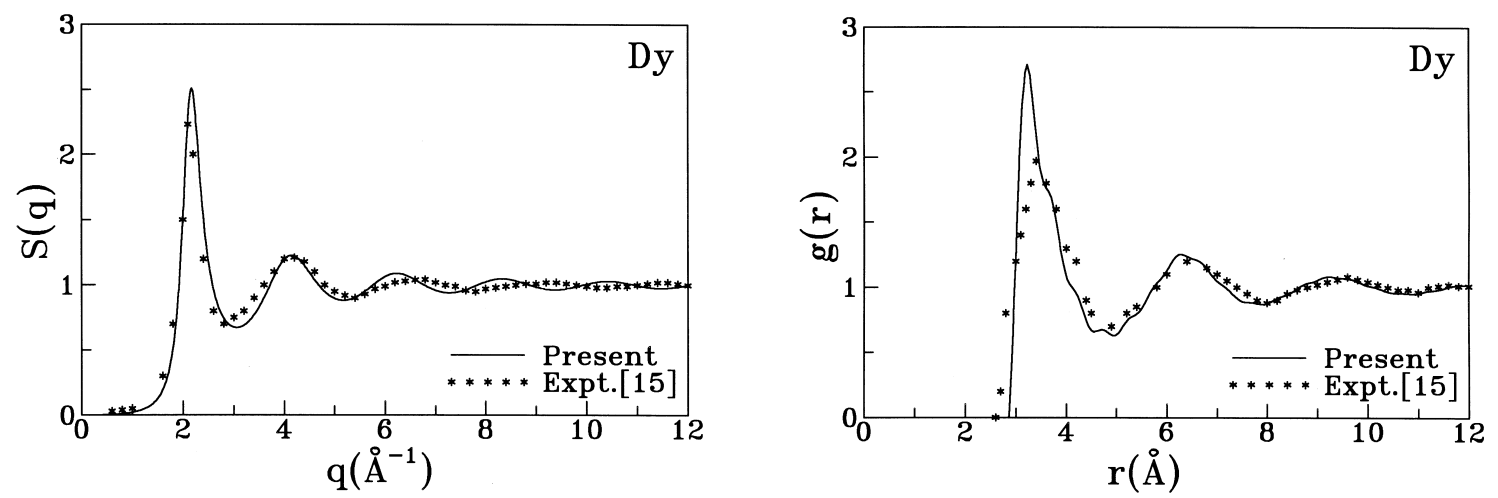

Figure 2. Structure factor, $S(q)$ and radial distribution function, $g(r)$ for Dy at $1703 \mathrm{~K}$.
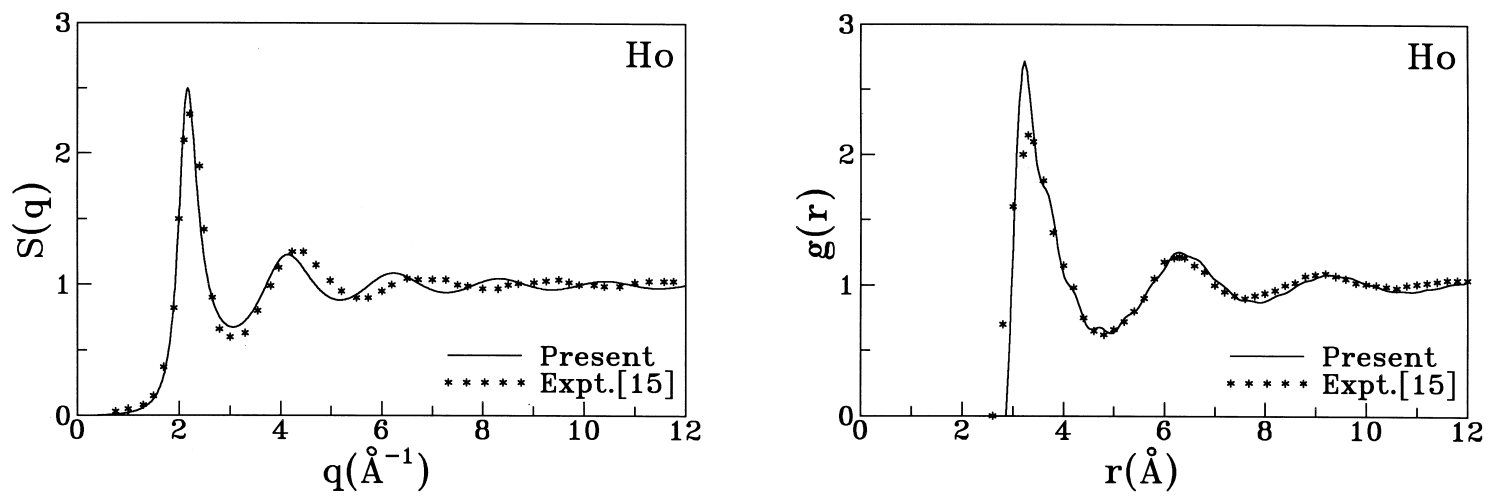

Figure 3. Structure factor, $S(q)$ and radial distribution function, $g(r)$ for Ho at $1753 \mathrm{~K}$. 

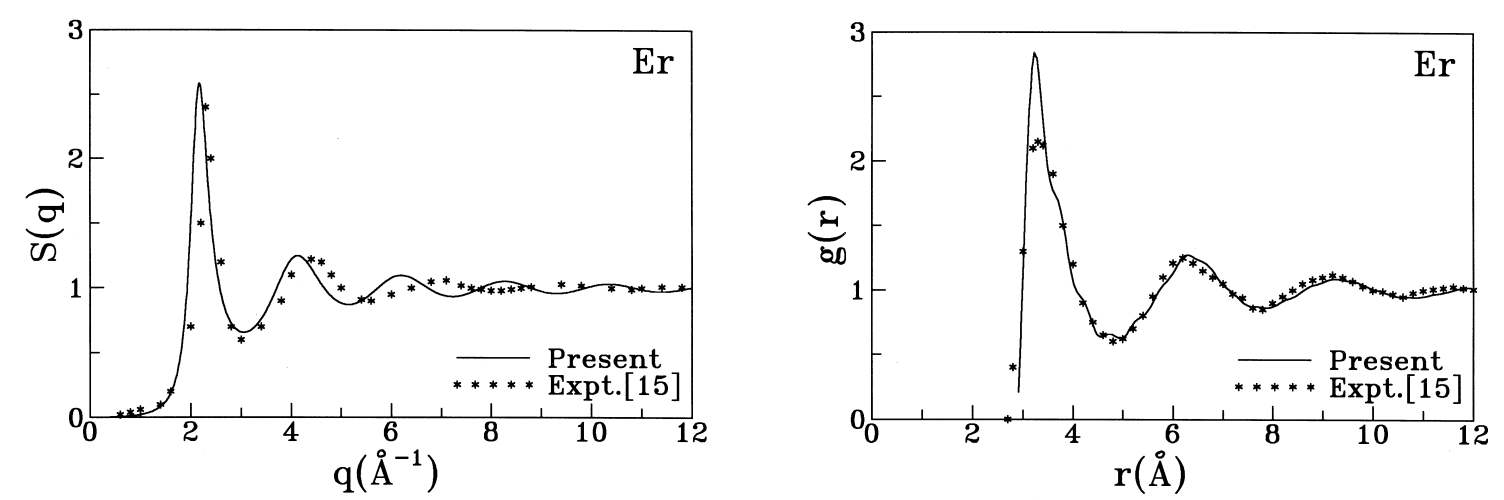

Figure 4. Structure factor, $S(q)$ and radial distribution function, $g(r)$ for Er at $1793 \mathrm{~K}$.
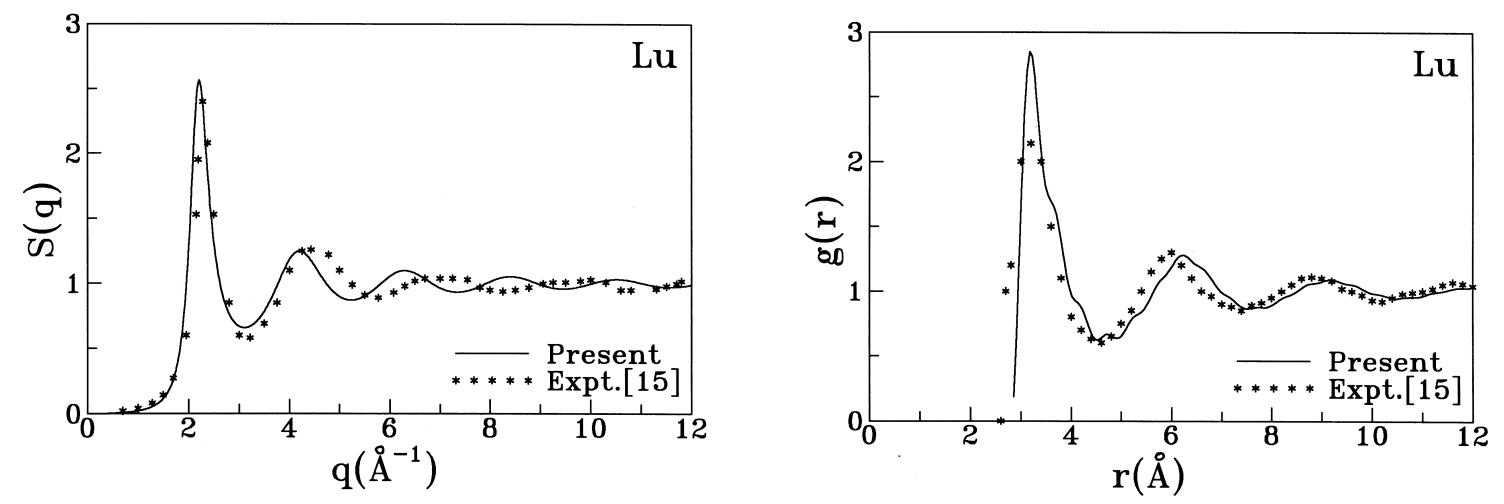

Figure 5. Structure factor, $S(q)$ and radial distribution function, $g(r)$ for Lu at $1953 \mathrm{~K}$.

Table 2. Position of first and second peak in $S(q)\left(\AA^{-1}\right)$ and interatomic distance $\left(r_{1}\right)$.

\begin{tabular}{|c|c|c|c|c|c|c|c|}
\hline \multirow{2}{*}{ Metal } & \multicolumn{3}{|c|}{ Peak positions in $S(q)\left(\AA^{-1}\right)$} & \multicolumn{3}{|c|}{ Interatomic distance $\mathrm{r}_{1}(\AA)$} \\
\cline { 2 - 5 } & \multicolumn{2}{|c|}{ First } & \multicolumn{2}{|c|}{ Second } & \multicolumn{2}{|c}{} \\
\cline { 2 - 7 } & Present & Expt.[15] & Present & Expt.[15] & Present & Other[3] & Expt.[15] \\
\hline Nd & 2.116 & 2.10 & 4.081 & 4.23 & 3.227 & 3.50 & 3.45 \\
\hline Dy & 2.173 & 2.12 & 4.138 & 4.03 & 3.227 & 3.40 & 3.43 \\
\hline Ho & 2.173 & 2.21 & 4.138 & 4.35 & 3.227 & 3.40 & 3.32 \\
\hline Er & 2.173 & 2.24 & 4.138 & 4.38 & 3.227 & 3.50 & 3.28 \\
\hline Lu & 2.210 & 2.28 & 4.195 & 4.43 & 3.175 & 3.40 & 3.22 \\
\hline
\end{tabular}


In table 2, we have compared the position of the first and the second peaks in $S(q)$ with experimental results of Waseda and Miller [15].

The deviation of the presently generated results from experimental data at the first peaks of $S(q)$ are of the order of 0.16 to 0.27 . Similarly, for $g(r)$ these deviations are of the order of 0.52 to 0.74 . For all the five liquid rare earth metals, the magnitude of the first peak in $S(q)$ and $g(r)$ is slightly higher than the experimental data, but the position of the first and second peaks in $S(q)$ is well estimated.

The interatomic distance $r_{1}$ of the nearest neighbour atoms is also investigated and compared with other theoretical [3] as well as experimental findings [15] in table 2. The excellent qualitative agreement between present and experimental findings is obtained.

Gopala Rao and Bandyopadhyay [3] have chosen $Z, r_{\mathrm{c}}$ and $\sigma$ in such a way that it generates satisfactory structural data. They have fitted these three parameters to obtain correct experimental predictions. However, the present investigation is free from such kind of a fitting procedure. In the previously reported study of liquid rare earth metals, the uncertainty in the data $Z$ is observed. Delley et al. [16] have estimated $Z=1.3$, Duthie and Pettifor [17] have estimated the value $Z=1.1$ to 1.5. Waseda and Miller [15] have estimated $Z=1.33$ to 2.09 for Lu. For Lu, Delley et al. [16] have suggested $Z$ closer to two. While Johansson [18] have assumed $Z=3.0$. Gopala Rao and Bandyopadhyay [3] have taken $Z=1.54$ to 2.03 to obtain a better agreement with the experimental findings. Thus, instead of making an adjustment in $Z$, we have considered $Z=1.5$ for all the five liquid rare earth metals and the uncertainty in the parameters is totally avoided, consistently.

And finally we conclude that, though the present computation is free from any artificial fitting procedure to predict correct experimental data, it is capable of explaining very good results for the structural data of liquid rare earth metals. Hence, the reported data are more meaningful and will provide a better source for further comparison either with theoretical or with experimental data. This confirms the applicability of our model potential and CHS method for predicting the structural studies of the liquid rare earth metals.

\section{Acknowledgement}

The work is supported under the special assistance programme at the level of Departmental Research Support by the University Grants Commission, New Delhi, India.

\section{References}

1. Lai S.K., Akinlade O., Tosi M.P. Thermodynamics and structure of liquid alkali metals from the charged-hard-sphere reference fluid. // Physical Review A, 1990, vol. 41, p. $5482-5490$.

2. Akinlade O., Lai S.K., Tosi M.P. Thermodynamics and structure of liquid metals from the charged-hard-sphere reference fluid. // Physica B, 1990, vol. 167, p. 61-70. 
3. Gopal Rao R.V., Bandyopadhyay U. Structural studies of some rare earth metals through palmer-weeks charged hard sphere model approximation. // Indian J. Phys., 1991, vol. 65A, p. 286-292.

4. Singh H.B., Holz A. Structure factor of liquid alkali metals. // Physical Review A, 1983, vol. 28, p. 1108-1113.

5. Palmer R.G., Weeks J.D., Jr. Exact solution of the mean spherical model for charged hard spheres in a uniform neutralizing background. // Chem. Phys, 1973, vol. 58, p. 4171-4174.

6. Thakor P.B., Joshi Tejal R., Thakore B.Y., Gajjar P.N., Jani A.R. Structure factor and radial distribution function of alkali metals by charged hard sphere model. // Solid State Physics Universities Press, Indian, 1999, vol. 42, p. 281-282.

7. Thakor P.B., Gajjar P.N., Jani A.R. Thermodynamic properties of liquid alkali metals. // Condens. Matter Phys., 2001, vol. 4, No. 3(27), p. 473-480.

8. Gajjar P.N., Thakore B.Y., Jani A.R. Total crystal energy and heat of solution of alkali based binary alloys. // Acta Phys. Pol. A, 2001, vol. 99, p. 565-578.

9. Thakor P.B., Gajjar P.N., Jani A.R. Temperature dependence of thermodynamic properties of liquid alkali metals. // Indian J. Pure \& Appl. Phys., 2000, vol. 38, p. 811-814.

10. Gajjar P.N., Thakore B.Y., Luhar J.S., Jani A.R. Residual resistivity due to vacancies in alkali metals. // Acta Phys. Pol. A, 1994, vol. 86, p. 369-374.

11. Avte R.S., Gajjar P.N., Jani A.R. Contribution of a point defect to the electrical resistivity of some polyvalent metals. // Phys. stat. sol. (b), 1993, vol. 176, p. K59K61.

12. Jani A.R., Gajjar P.N., Patel H.K. Susceptibility of some simple metals by local pseudopotentials. // Phys. stat. sol. (b), 1992, vol. 169, p. K105-K108.

13. Heine V., Weaire D. Solid State Physics. New York, Academic press, 1970, vol. 24, p. 419.

14. Taylor R. A simple, useful analytical form of the static electron gas dielectric function. // J. Phys. F: Metal Phys, 1978, vol. 8, p. 1699-1702.

15. Waseda Y., Miller W. A. A structural study of some liquid rare earth metals (Nd, Dy, Ho, Er and Lu). // Philosophical Magazine B, 1978, vol. 38, p. 21-24.

16. Delley B., Bech H., Kunzi H.U., Guntherodt H.J. Evidence for varying $d$-band occupancy across the trivalent rare earth series. // Phys. Rev. Lett, 1978, vol. 40, p. 193197.

17. Duthie J.C., Pettifor D.G. Correlation between $d$-band occupancy and crystal structure in the rare earths. // Phys. Rev. Lett, 1977, vol. 38. p. 564-567.

18. Johansson B. The boiling points of the rare earth metals. // J. Phys. F, 1975, vol. 5, p. $1241-1247$. 


\title{
Вивчення структури рідких рідкоземельних металів на основі флюїду заряджених твердих сфер
}

\author{
П.Б.Факор, П.Н.Гедджар, А.Р.Дженай
}

Університет ім. Сердара Пейтела, фізичний факультет

Валлабх Відянагар-388120, Гуджарат, Індія

Отримано 27 серпня 2001 р.

В даній статті вивчаються структурний фактор $s(q)$, радіальна функція розподілу $g(r)$ і міжатомна відстань $r_{1}$ рідкоземельних рідкихметалів Nd, Dy, Ho, Er i Lu на основі флюїду заряджених твердих сфер. Для опису взаємодії електрон-іон використовується наш модельний потенціал разом з діелектричною функцією Тейлора. Робиться висновок про добре узгодження отриманих результатів з експериментальними.

Ключові слова: псевдопотенціал, структурний фактор, радіальна функція розподілу, рідкоземельні метали

PACS: $71.15 . H, 61.25 . M$ 
